\title{
Dental Anxiety among Danish Adults -Comparison of Recent Website Data and older Telephone Data with Government Demographic Statistics
}

\author{
Rod Moore', Peter Bering² \\ ${ }^{1}$ Dental Anxiety Research \& Treatment Center, Department of Dentistry, Aarhus University, Aarhus, Denmark \\ ${ }^{2}$ Department of Public Health Sciences, Aarhus University, Aarhus, Denmark \\ Email: rod.moore@dent.au.dk, bering101@gmail.com
}

How to cite this paper: Moore, R. and Bering, P. (2017) Dental Anxiety among Danish Adults-Comparison of Recent Website Data and Older Telephone Data with Government Demographic Statistics. Open Journal of Stomatology, 7, 530-544. https://doi.org/10.4236/ojst.2017.712050

Received: November 24, 2017 Accepted: December 26, 2017 Published: December 29, 2017

Copyright $\odot 2017$ by authors and Scientific Research Publishing Inc. This work is licensed under the Creative Commons Attribution International License (CC BY 4.0).

http://creativecommons.org/licenses/by/4.0/ (c) (i) Open Access

\begin{abstract}
Background: Survey quality, in particular sampling, coverage, and issues of representativity, are important for valid and reliable conclusions from epidemiological data. Dental anxiety (DA) still challenges dental clinicians since it is synonymous with care avoidance. Accurate estimates of DA are important for public health. Aims were to 1) assess demographic representativity (age/ gender) of a 2013-14 web survey and a 1992-93 telephone survey about DA in Danish adults aged 16 - $80 \mathrm{yr}$ using government statistics; 2) assess DA frequency and characteristics from web survey data $(\mathrm{N}=701)$; and 3) compare web results with 1993 results. Method: Dental Anxiety Scale (DAS) measured DA, while other items revealed gender, age, education, dentist avoidance, and three types of negative dentist behaviors. Analyses used frequencies, Chisquare, odds ratios (OR) and ANOVAs. Results: Samples from 1992-3 and 2013-14 were not significantly different by demographics or government statistics, with the exception of low numbers in ages $16-19 \mathrm{yr}$ for both surveys. Ages $20-29 \mathrm{yr}$ and $30-39 \mathrm{yr}$ were slightly overrepresented in telephone data, while ages 50 - 59 yo were in web data. Mean DAS scores were 7.5 for both 1992-3 and 2013-14. Extreme DA (DAS 20-15) increased from $4.2 \%$ to $5.3 \%$, while high DA (DAS $\geq 13$ ) increased from 6\% to 9.5\%. Main 2013-14 associations with $\mathrm{DAS} \geq 15$ were women $(\mathrm{OR}=4.7)$, avoiding dentists $(\mathrm{OR}=11.4)$ and negative dentist behaviors $(\mathrm{OR}=4.2-6.7)$ similar to $1992-3$ data. Conclusion: Web survey results from this convenience sample were demographically representative for adults 20 - 80 yo and showed small changes in DA after 20 years. Future strategies regarding survey of teenagers require special attention.
\end{abstract}




\section{Keywords}

Dental Anxiety, Prevalence, Characteristics, Epidemiological Methods, Subject Recruitment, Web Surveys, Telephone Surveys, Demographic Representativity

\section{Introduction}

In the present decade, after greater and greater use of mobile telephones each passing decade, the Danish land line telephone system is no longer able to uphold the basic required survey research assumption that almost all Danish households have land line phones. Therefore, one alternative survey strategy that seems feasible is use of web surveys. Web surveys have been described as more cost effective than telephone surveys [1]. Findings are not adversely affected by non-serious or repeat responders, and are consistent with findings from traditional methods [2] [3]. Survey methods should always consider survey quality and in particular sampling, coverage, nonresponse, measurement error and issues of representativity [1] [2] [4] [5]. This is as true today with web survey methods as it was in previous decades when randomized conventional telephone surveying was the primary modus operandi.

This paper focuses on assessment of possible changes in dental anxiety (DA) prevalence through time using two different research strategies, while also assessing the comparability of those strategies, samplings and their results. Anxiety about dental treatment still challenges Danish dental clinics, since people with even a moderate degree of dental fear are more likely to skip or cancel appointments. Thus, accurate information as to prevalence and characteristics of dental anxiety (DA) among populations are important for public health planning and mobilization.

A study [6] published in 1993 showed that $4.2 \%$ of Danish adults totally avoided dental treatment due to extreme anxiety, while $6.0 \%$ reported moderate anxiety for dental treatment that resulted in sporadic visits to the dentist. Another 29.5\% had some to little anxiety. The Dental Anxiety Scale (DAS) [7] [8], was used in that study to determine extreme DA (DAS $\leq 15)$, moderate DA (DAS 14 - 12) and some DA (11 - 8). At the end of 2013 and beginning of 2014, a web-site survey of DA in Danish adults was used to collect data, including DAS, to form the basis for development of a patient-centered smart-phone application ("Cope it") to examine and help treat DA [9]. A collaboration between the app-company and Aarhus University, School of Dentistry led to an opportunity to examine epidemiological data from the web survey and compare it with data collected in 1992.

Specific aims of the present study were 1) to compare 2013-14 web survey data with a telephone survey from 1992 by demographics as well as overall demographic representativity (age and gender) of Danes aged $16-80 \mathrm{yr}$ for those 
times using statistics available from the government; 2) to assess frequency and characteristics of DA in Danish adults from the web survey of 701 Danish adults; and 3) to compare results from these two samples for prevalence or characteristics of DA over time.

\section{Materials and Methods}

\subsection{Sampling and Populations}

The survey population in Moore et al.'s randomized telephone survey reported in 1993 [6] was described as representative for the adult Danish population, since Aarhus, the second largest municipality in Denmark and its surrounding areas consisted of urban and rural areas in a distribution, similar to Denmark in general. The present web survey convenience sample $(\mathrm{N}=701)$ used many of the same measures as in the 1993 data [6] [10]. Web survey respondents were solicited by e-mail from lists of patients past and present from 4 dental practices in Copenhagen, Aarhus, Kolding and Grindsted with a potential population base of over 6000 persons. These sites provided a mix of urban and rural residents similar to the 1993 study. Subjects were Danish speaking and only identifiable by age, gender and educational level. Software from SurveyMonkey Inc., San Mateo, California, USA was used via survey links sent via the e-mails. The e-mails solicited subjects with the message, "Since you are or have been a patient at our clinic, we ask you to participate in a questionnaire study. Your responses will be used to develop a smart-phone application to better aid both patients and dentists in dealing with dental fear problems. So please answer even if you do not necessarily feel that you are afraid of dentists." All subjects participated on an anonymous, voluntary basis and met ethics criteria for Aarhus municipality ethics committee.

\subsection{Survey Items}

The original web survey consisted of 95 closed-ended questions. Of these, only 12 items were applicable to the present prevalence study and occurred at the beginning of the survey. The other questions were only relevant to development of the smart-phone application and focused on characteristics of selected anxious subjects, their relationship with their dentist and their use of coping strategies. While these 83 items are of interest for future studies of DA incidence, they could not be used for a prevalence investigation. Of the 12 items usable for prevalence, three were standard demographic items and four items assessed dental anxiety as described below. One item asked if subjects presently had a dentist. Three items assessed difficulties in dentist-patient relating by asking if subjects "felt the dentist was angry with me", "felt put down", and "received a "hardhanded' treatment". Finally, a single item was used to judge the subjects' subjective assessment of their DA level, which would be used to co-validate the following DA scale. 


\subsection{Dental Anxiety Scale}

The dependent variable used in the study was Corah's Dental Anxiety Scale (DAS) [7] [8] which is a widely recognized trait anxiety measure about dental treatment. It consists of 4 items that indicate situations associated with dental treatment: How would you feel if you should: "go to the dentist tomorrow", "wait in the waiting room", "sit in the dental chair while the dentist makes the drill ready" and "...get tooth cleaning". Subjects responded to each of the questions on a Likert scale from 1 to 5 , where 1 was equivalent to relaxed and 5 was equivalent to very anxious. Thus, DAS has a maximum score of 20 , which indicates extreme anxiety and a minimum of 4 indicating no anxiety. Previous studies have determined that DAS has high validity and reliability as a measure of intensity of DA in Danish populations [6] [11]. In this web survey, the DAS questions (in Danish) were exactly the same as for subjects in Moore et al.'s 1993 study [6]. Cut-offs for categories of intensity of DA were determined by reference to the literature on DAS in epidemiological studies [6] [10] [12]. For analyses, "high DA" was used as the dichotomous DAS cutoff $\geq 13$ vs. $<13$ [12], recommended by Corah et al. These high anxiety data were not reported in the 1993 study, but were available to the principal author for the present analysis. "Extreme or phobic DA" cut-off was DAS $\geq 15$ vs. $<15$, as in the 1993 study. DAS 12 - 14 was reported as "moderate DA", DAS $\leq 11$ was "some" and DAS 4 7 was little to no anxiety, as in 1993 reports [6].

\subsection{Independent Variables}

The three demographic items were gender, age in whole years, and education and were comparable to the 1993 study. Educational level of respondents was judged by an ordinal scale from $1=$ Grade school or none, $2=$ High school graduate, $3=$ Technical, $4=$ Vocational continuing education $<3 \mathrm{yr}, 5=$ Higher education $3-4 \mathrm{yr}$ and $6=$ Higher education $\geq 5 \mathrm{yr}$. The item, "Do you have a dentist that you turn to for regular checkups or emergencies?" was scored "yes" or "no". Three items assessing difficulties in dentist-patient relating were: "How often have you experienced that your dentist is angry or irritated with you?", "How often have you experienced that your dentist has talked down to you in a demeaning way ('put down')?" and "How often have you experienced a hardhanded treatment at the dentist?". Respondents rated these by $1=$ Never, $2=$ Rarely, $3=$ Sometimes, $4=$ Often, or $5=$ Almost every time. All variables above were subsequently dichotomized for odds ratio and CI calculations related to DA. The cut-offs were made between "Rarely" and "Sometimes" for the dentistpatient variables. "High education" was cut-off at $\geq 5$.

The single item used to co-validate DAS was: "Are you worried, nervous or anxious about going to the dentist?" where $1=$ "No", 2 = "No, but I have earlier", 3 = "Yes, but not very much", 4 = "Yes, I feel it is very unpleasant", 5 = "Yes, I am extremely worried and nervous" and $6=$ "Yes, I am so anxious that I can experience panic". 


\subsection{Statistical Methods}

DA was analyzed for associations using DAS $\geq 13$ (high anxiety) and $\geq 15$ (extreme anxiety) versus all other dichotomous variables where appropriate. Comparisons were made using frequencies, Chi-square $\left(\mathrm{Chi}^{2}\right)$ tests, odds ratios, Spearman's rho and ANOVAs. Trend analyses were solved using ANOVAs and $\mathrm{Chi}^{2}$ goodness of fit. Significance testing was performed using two-tailed $\mathrm{P}$ value of 0.05 , while $95 \%$ confidence intervals (CI) were presented in odds ratio analyses, for further clarification. DAS was co-validated by Spearman's correlation. Analyzes were aided by SPSS 24 software.

\section{Results}

An analysis of the web survey sample demographics was compared with Moore et al. [6] and of these studies compared with actual Danish population demographics of each time period. Thereafter, follow results of the analysis of the occurrence of DA in 2013-14, which is then compared with frequencies described in the 1993 published study.

\subsection{The Study Samples}

The women $(\mathrm{n}=274)$ to men $(\mathrm{n}=266)$ ratio in 1992 compared with women ( $\mathrm{n}$ $=378)$ to men $(\mathrm{n}=323)$ in 2013-14 with no significant difference $\left(\mathrm{Chi}^{2}=1.2,1\right.$ $\mathrm{df}, \mathrm{P}=0.27$ ). There was no significant difference between gender ratios for 1992 sample data and the actual Danish population gender ratio for January 1992 for adults $16-80$ yo $\left(\mathrm{Chi}^{2}=0.02,1 \mathrm{df}, \mathrm{P}=0.88\right)$. Nor was the gender ratio of the 2013-14 sample significantly different from the actual Danish population gender ratio for January $2014\left(\mathrm{Chi}^{2}=3.6,1 \mathrm{df}, \mathrm{P}=0.06\right)$. Mean age of the sample in 1992 was 43.8 yo $(\mathrm{SD}=17.0)$. Mean age of the sample in $2013-14$ was $49.0(\mathrm{SD}=$ 16.1). Figure 1 compares age groups by percentages from 2013-14 sample data and 1992 data in the columns, while the lines in the graph represent the actual Danish adult age group distributions for each of the study years at January 1.

Sampling and true population comparisons by gender and age are also found in more detail in Figure 2 and Figure 3. Sample distributions by age and gender distribution approximate the true population distribution with some exceptions. A deficiency of 16 - 19 yo subjects in both samples, relative to true population distributions, was the main exception. The 50 - 59 yo group in 2013-14 (Figure 1 and Figure 2) was slightly overrepresented, compared to the true population.

In telephone survey sampling, groups $20-29$ yo and $30-39$ yo were slightly overrepresented compared to the true population (Figure 1 and Figure 3).

For comparison, Denmark's Statistical Bank (http://www.statbank.dk/BEF5) showed a total of 4,910,189 ethnic Danes of all ages in January $1992(2,421,971$ males/2,488,218 females) and 5,056,810 in January 2014 (2,515,426 males/ 2,541,384 females).

Given that web survey data were collected from e-mail lists of dentists, and that subjects were also asked to respond to "Do you have a dentist that you turn 


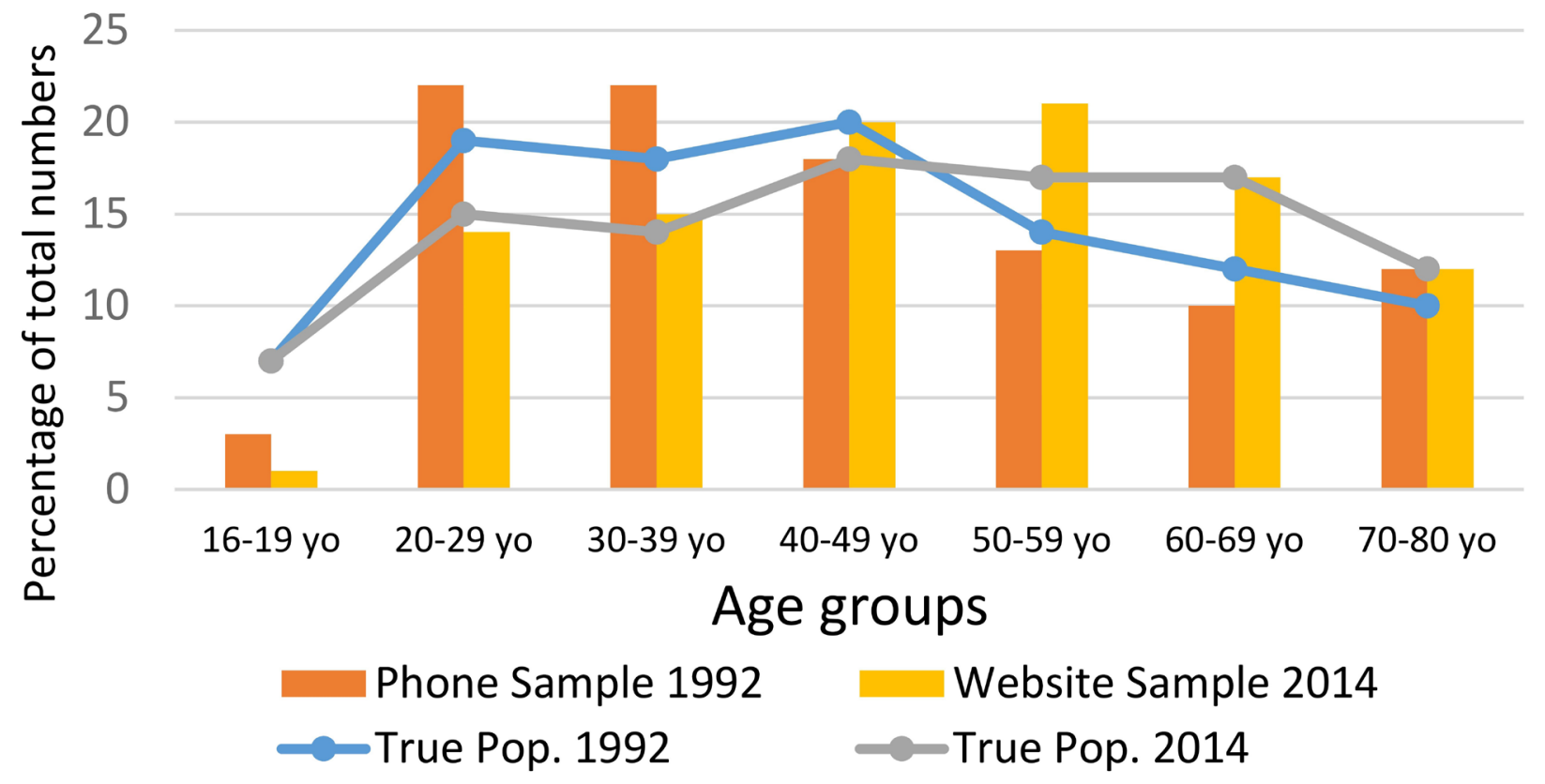

Figure 1. Age groups of samples in columns compared with actual Danish demographics in lines.
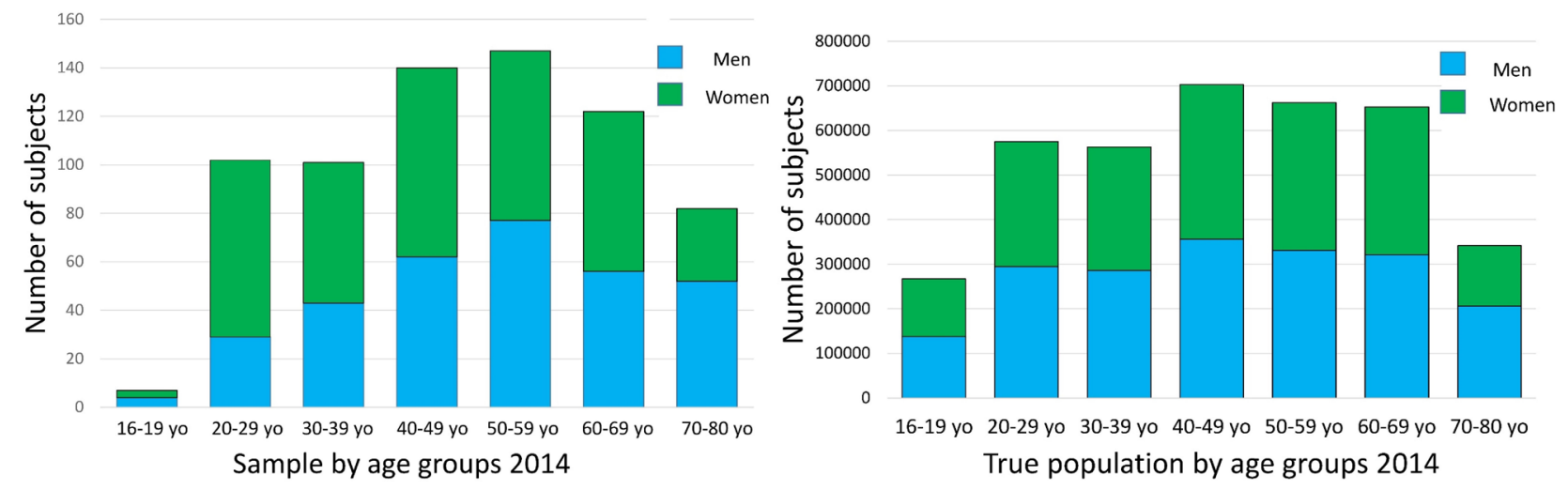

Figure 2. Age and gender distributions in the 2013-2014 study $(\mathrm{N}=701)$ and Danish government equivalent $(\mathrm{N}=3,864,645 ; \mathrm{Men}$ $=1,933,768$; Women $=1,930,877)$.
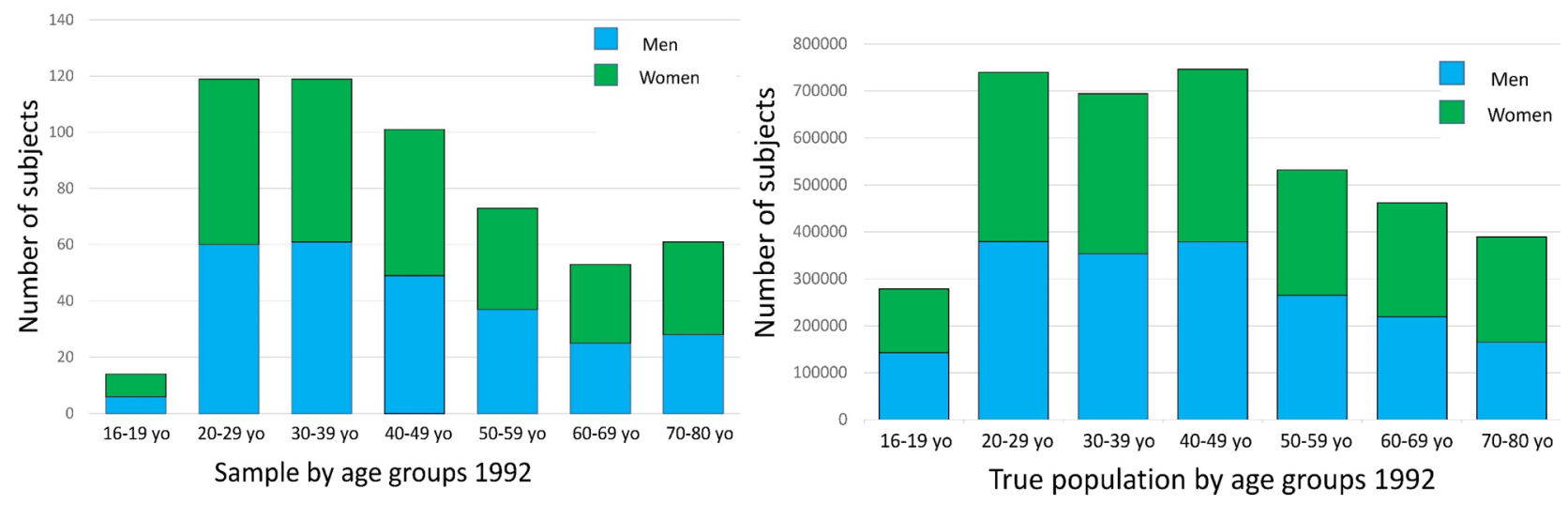

Figure 3. Age and gender distributions in the 1992 study $(\mathrm{N}=540)$ and Danish government equivalent $(\mathrm{N}=3,841,836 ; \mathrm{Men}=$ $1,905,048$; Women $=1,936,788$ ). 
to for regular checkups or emergencies?", an analysis of responses was important to establish a possible bias from recruitment. Responses from present or former dental patients' e-mails yielded 11 "no" responses and 690 "yes" responses or $1.6 \%$ of the total sample, which in later analyses provided ample information about characteristics of high or extreme DA compared with 1992.

\subsection{Dental Anxiety by Characteristics}

In co-validation analysis of DAS total scores, Spearman's rho with the single item anxiety index was $0.80, \mathrm{P}<0.001$. Danish adult DA distributions in the present study were compared with those of results from the 1993 study in Table 1.

Women reported a higher average DAS score $(\mathrm{DAS}$ mean $=8.2 ; \mathrm{SD}=3.9$ ) than men $(\mathrm{DAS}$ mean $=6.8 ; \mathrm{SD}=2.7)(\mathrm{F}=29.3$, DF $=1, \mathrm{P}<0.001)$ ANOVA results also showed a significant difference between age groups and total DAS scores $(\mathrm{F}=4.2 ; \mathrm{df}=6 ; \mathrm{P}<0.001)$. Examination of DAS means by age group indicated that dichotomous cut-off points before and after age 50 would be beneficial for odds ratio and CI calculations in bivariate analyses below.

Table 2 presents data for DA levels of subjects by gender and age groups described above.

Table 3 results show that subjects with lower educational levels did not have significantly more frequent "high anxiety" levels than those with a higher educational level, whereas they did have significantly more frequent extreme DA (DAS $\geq 15$ ). Consequently, the first four educational levels were chosen to define lower education level, while the last two (medium and long term higher education) were defined as higher education and this was made into a dichotomous variable to also be tested in bivariate analyses below.

Table 1. Comparisons of Danish adult DA distribution in 1993 and 2013-14 by DAS scores.

\begin{tabular}{|c|c|c|c|c|}
\hline \multirow{2}{*}{$\begin{array}{l}\text { High Dental } \\
\text { Anxiety: }\end{array}$} & \multicolumn{2}{|c|}{1993} & \multicolumn{2}{|c|}{ 2013-14 } \\
\hline & $\mathrm{n}$ & Valid \% & $\mathrm{n}$ & Valid \% \\
\hline $\mathrm{DAS} \geq 13$ & 31 & $6.0 \%$ & 67 & $9.6 \%$ \\
\hline $\mathrm{DAS}<13$ & 508 & $94.0 \%$ & 634 & $90.4 \%$ \\
\hline Total & $\mathrm{N}=539$ & $100 \%$ & $\mathrm{~N}=701$ & $100 \%$ \\
\hline \multirow{2}{*}{$\begin{array}{c}\text { Extreme Dental } \\
\text { Anxiety: }\end{array}$} & \multicolumn{2}{|c|}{1993} & \multicolumn{2}{|c|}{ 2013-14 } \\
\hline & $\mathrm{n}$ & Valid \% & $\mathbf{n}$ & Valid \% \\
\hline $\mathrm{DAS} \geq 15$ & 23 & $4.2 \%$ & 37 & $5.3 \%$ \\
\hline DAS $12-14$ & 32 & $6.0 \%$ & 57 & $8.1 \%$ \\
\hline DAS 8 - 11 & 159 & $29.5 \%$ & 157 & $22.4 \%$ \\
\hline DAS $4-7$ & 325 & $60.2 \%$ & 450 & $64.2 \%$ \\
\hline Total & $\mathrm{N}=539$ & $100 \%$ & $\mathrm{~N}=701$ & $100 \%$ \\
\hline
\end{tabular}

$D A S \geq 13: \mathrm{Chi}^{2}=8.1, \mathrm{df}=1, \mathrm{P}<0.01, D A S \geq 15: \mathrm{Chi}^{2}=2.2, \mathrm{df}=1, \mathrm{P}=0.14$. 
Table 4 presents odds ratio and confidence intervals at $95 \%$ for the selected bivariate analyses with DAS $\geq 13$ and DAS $\geq 15$.

\section{Discussion}

Although internet technology provides significant opportunities for innovation in survey design, systematic research has yet to be conducted on how to get the most of possible design innovations. Thanks to a data registry made available by the Danish government, we were able to examine and test a hypothesis that demographic variables of gender and age for the two survey approaches were representative of the true adult populations of January 1, 1992 and January 1, 2014, both within the respective data collection periods. The two survey strategies conducted in 1992 and 2013-14 showed no significant age or gender differences with their respective true Danish populations aged 20 - 80 yr. It is noteworthy

Table 2. Frequencies, $\mathrm{Chi}^{2}$ and likelihood by gender and age groups for high and extreme dental anxiety, $\mathrm{N}=701$.

\begin{tabular}{cccccccccc}
\hline \multicolumn{1}{c}{ Gender } & \multicolumn{7}{c}{ Age } \\
\hline High & Women & Men & $16-19$ & $20-29$ & $30-39$ & $40-49$ & $50-59$ & $60-69$ & $70-80$ \\
DAS $\geq 13$ & 51 & 16 & 3 & 19 & 8 & 16 & 13 & 6 & 2 \\
DAS $<13$ & 327 & 307 & 4 & 83 & 93 & 124 & 134 & 116 & 80 \\
Total & 378 & 323 & 7 & 102 & 101 & 140 & 122 & 82 & 87 \\
\hline
\end{tabular}

$\mathrm{Chi}^{2}=14.7, \mathrm{df}=1, \mathrm{P}_{\text {Gender }}<0.001, \mathrm{Chi}^{2}$ fit $=24.4, \mathrm{df}=6, \mathrm{P}_{\text {Age }}<0.001$.

\begin{tabular}{cccccccccc}
\hline \multicolumn{1}{c}{ Gender } & \multicolumn{7}{c}{ Age } \\
\hline Extreme & Women & Men & $16-19$ & $20-29$ & $30-39$ & $40-49$ & $50-59$ & $60-69$ & $70-80$ \\
DAS $\geq 15$ & 31 & 6 & 2 & 12 & 5 & 7 & 5 & 5 & 1 \\
DAS $<15$ & 347 & 317 & 5 & 90 & 96 & 133 & 142 & 117 & 81 \\
Total & 378 & 323 & 7 & 102 & 101 & 140 & 147 & 122 & 82 \\
\hline $\mathrm{Chi}^{2}=14.0, \mathrm{df}=1, \mathrm{P}_{\mathrm{G}}<0.001, \mathrm{Chi}^{2} \mathrm{fit}=15.9, \mathrm{df}=6, \mathrm{P}_{\mathrm{Age}}=0.02$.
\end{tabular}

Table 3. Frequencies and likelihood ratios of DA by 2013-14 educational level for web survey data $\mathrm{N}=701$.

\begin{tabular}{cccccc}
\hline Educational level: & DAS $\geq 13$ & DAS $<13$ & DAS $\geq 15$ & DAS $<15$ & Total \\
\hline Grade school or none & 8 & 55 & 6 & 57 & 63 \\
High school graduate & 10 & 41 & 6 & 45 & 51 \\
Technical school & 15 & 143 & 7 & 151 & 158 \\
Vocational continuing education & 13 & 91 & 8 & 96 & 104 \\
Higher education 3 - 4 yr & 17 & 189 & 9 & 197 & 206 \\
Higher education $\geq \mathbf{5}$ yr & 4 & 115 & 1 & 119 & 119 \\
Total & 67 & 634 & 37 & 664 & 701 \\
\hline
\end{tabular}

$\mathrm{Chi}^{2}$ fit $=13.6, \mathrm{df}=6, \mathrm{P}=0.02, \mathrm{Chi}^{2}$ fit $=13.9, \mathrm{df}=6, \mathrm{P}=0.02$. 
Table 4. Odds ratios and CI for DA characteristics for high anxiety and extreme anxiety, $\mathrm{N}=701$. Significance level is indicated at ${ }^{*}<0.05,{ }^{* *}<0.01$ and ${ }^{* * *}<0.001$ in the table.

\begin{tabular}{ccccccc}
\hline \multirow{2}{*}{ Characteristics } & \multicolumn{3}{c}{ DAS $\geq 13$} & \multicolumn{3}{c}{ DAS $\geq 15$} \\
\cline { 2 - 7 } & $\mathbf{n}$ & OR & $95 \% \mathrm{CI}$ & $\mathbf{n}$ & OR & $95 \% \mathrm{CI}$ \\
\hline Women & $51 / 67$ & $3.0^{* * *}$ & $1.7-5.4$ & $31 / 37$ & $4.7^{* * *}$ & $1.9-11.5$ \\
Age $<50$ & $46 / 67$ & $2.4^{* * *}$ & $1.4-4.1$ & $26 / 37$ & $2.5^{* *}$ & $1.2-5.1$ \\
Less educated & $46 / 67$ & $2.0^{* *}$ & $1.2-3.5$ & $27 / 37$ & $2.4^{*}$ & $1.2-5.1$ \\
Have no dentist & $5 / 67$ & $8.4^{* * *}$ & $2.5-28.5$ & $4 / 37$ & $11.4^{* * *}$ & $3.2-40.8$ \\
Angry or irritated dentist & $19 / 67$ & $4.6^{* * *}$ & $2.5-8.5$ & $14 / 37$ & $6.7^{* * *}$ & $3.3-13.8$ \\
$\begin{array}{c}\text { Demeaning dentists. } \\
\text { "put downs" }\end{array}$ & $18 / 67$ & $3.5^{* * *}$ & $1.9-6.3$ & $13 / 37$ & $4.9^{* * *}$ & $2.4-10.1$ \\
$\begin{array}{c}\text { Hard-handed dentist } \\
\text { Hard }\end{array}$ & $43 / 67$ & $2.9^{* * *}$ & $1.7-4.9$ & $27 / 37$ & $4.3^{* * *}$ & $2.0-8.9$ \\
\hline
\end{tabular}

that there were demographic changes in the Danish population from 1992 to 2014, as can be seen in Figures 1-3. It is meaningful that the general adult population lived to be older in 2014 compared with those in 1992. Regarding gender prevalence, in the 1992 data collection period for ages $16-80 \mathrm{yr}$, the true gender ratio was $1,905,048$ men to $1,936,788$ women, i.e. a difference of over 31,000 more women than men. This changed in 2014 with a ratio of $1,933,768$ men to 1,930,877 women aged $16-80 \mathrm{yr}$, where there was a smaller difference of over 3000 more men than women. It is noteworthy that total population figures for all ages of Danes in January 2014 did not reflect this gender ratio. Thus, age groups other than the selection of 16 - 80 yo apparently had a greater number of women.

Figures 1-3 show that frequencies in both samples were very low in the age group 16 - 19 yo compared to the respective true populations. This is a bit perplexing but perhaps understandable, since telephone surveys by households in the 1990s could miss teenagers. Also, since the majority of teenagers still receive care in the Danish children's public health system until age 18, participation in the 2013-14 survey from e-mail lists from private practices would more likely exclude recruitment of teenagers. This observation is important to any future epidemiological studies of DA, since specific strategies for recruitment of teenagers for studies must improve or else this age group should not be recruited simultaneously with the same strategy as for $20+$ yo subjects. Perhaps recruitment in children's public health clinics in separate studies could supplement older adult subject recruitment.

Eleven e-mail recruited subjects stated that they had no dentist, indicating that they had dropped out of the dental health care system and had high or extreme DA. Avoidance of going to the dentist is a hallmark behavioral indicator highly associated with high or extreme DA. Results of the analysis of web survey data showed a small increase in the rate of extreme DA and moderate DA in the Danish adult population while there was decreased frequency in "some" DA. Ex- 
treme anxiety (DAS 20 - 15) increased from $4.2 \%$ to $5.3 \%$. Moderate anxiety (DAS 14 - 12) increased from $6.0 \%$ to $8.1 \%$. Some anxiety (DAS 8 - 11) fell from $29.5 \%$ to $22.4 \%$, while little or no fear (DAS 4 - 7) increased from $60.2 \%$ to $64.2 \%$. In all, results showed a decrease in reported levels of at least some fear from $39.7 \%$ in 1993 to $35.8 \%$ in 2014 , but with a significant increase in high DA (DAS $\leq 13$ ), but not extreme DA as shown in Table 1 . Denmark is a small and homogeneous population group. The sampling is a convenience sample, that is to say, not randomly selected from the population. However, if it is argued from a demographic perspective that the two samples are representative of the adult populations aged $20-80 \mathrm{yr}$, and that these data likely covered urban and rural areas, then the results approach representativity regarding dental anxiety phenomena. There are some dynamics that have likely occurred in which DA levels have moved from "some anxiety" to moderate or higher levels by around $7 \%$, which appears to be statistically significant $\left(\mathrm{Chi}^{2}=8.1,1 \mathrm{df}, \mathrm{P}=0.004\right)$. However, since the present study presents a convenience sample and not a longitudinal cohort study, this will need to remain a hypothesis based on the limited assumptions and test variables of the two cross-sectional samples. Most studies, e.g. two separate cross-sectional studies (1990 and 2009) in the Netherlands [13] [14], one cohort study (2000-2011) in Finland [15], one meta-analysis (1955-2000) in the USA [16], and a Swedish cohort study of women (1968-1996) [17] report stable levels of DA and phobia over time. However, two large cross-sectional studies in Australia, one published in 1996 [18], and the second published in 2010 [19] used the same DAS 13 cut-off for high DA and found that prevalence had increased from $14.9 \%$ to $18.1 \%$. This increase was attributed to that during this 13 yr span people over 45 yo in 2008 were more dentulous compared to 1995, due to improved dental care. Thus, they had more opportunities to have bad experiences that could lead to DA. In the present results for Danes, the dental health care system has had a high level of subsidized care at all ages starting in the 1980s, and thus present day adults have perhaps retained their teeth longer and did so earlier than was the case in Australia. In the 1993 investigation of DA in the Danish adult population, data were originally collected on 645 subjects [6], but soon, as was the case in the Australian studies, it was also found that edentulousness introduced confounding into the analysis of DA prevalence. Edentulous subjects were less afraid of dentists since they had no teeth. Consequently, after a $12 \%$ dropout rate and selection of only dentulous subjects for DAS analyses, only 539 adults were eligible for a DA prevalence study. The present web survey did not ask respondents about edentulousness, but the premise was also that edentulousness was less common today compared to 1992. Still, since there was a difference in selection by dentulous/edentulous in 1993, it could be possible that there was edentulous confounding in the decreasing anxiety of subjects over 50 yo in the present study. No significant age influence was noted in DAS analyses in the 1992-3 study [6].

Longitudinal cohort studies of dental anxiety in adults are rare [15] [17] [20] 
[21]. Most longitudinal cohort studies have shown that as populations age, DA decreases [15] [17] [21]. A UK cross-sectional study of a very large sample also showed DA decreased markedly after age $54 \mathrm{yr}$ [22], as did a representative German sample [23]. These studies support the present web survey results that subjects over 50 yo experienced significantly lower levels of dental anxiety than younger subjects. Another explanation for decreased anxiety with age is that older adults apparently use emotional coping skills acquired through the years and thereby avoid negative reactions [24].

Other than age less than $50 \mathrm{yr}$, main results in 2013-14 by characteristics of those with high or extreme DA were women, no dentist, lower educational levels and experience with negative dentist behaviors, which is comparable to the 1993 study for those variables. But it should be pointed out that the present web survey was different from the telephone survey in 1992-3 in that there were no measures of general anxiety or psychiatric distress. This is a limitation of the present study, since the 1993 report indicated that subjects with extreme DA were nearly 6 times more likely to have high general fearfulness [6]. General psychological problems have also been found to be highly associated with high DA in other studies [10] [12]. A recent clinical epidemiological study comparing psychiatric patients with a normal clinical population [12] indicated that patients with psychiatric diagnoses were 3 times more likely to have high DA (DAS $\geq 13$ ) and nearly 2 times more likely to have avoided dental treatment for 2 years or more.

Present results regarding significant prevalence of high DA or phobia in women were similar in other countries, notably, Finland [15], the Netherlands [13], Germany [23] and Australia [19]. One reason there are higher reported rates of DA for women may be that women are reported to be more prone to anxiety or fear in general [13] [25]. Women are also known to be traditionally better at expressing concerns and feelings including anxiety [26]. In this regard, socialization processes of women are perhaps key to cultivation and promotion of processes related to anxiety [26] [27]. However, there is also another literature [28] that posits that since the neural basis of gender differences in anxiety perception remains unclear, and findings appear inconsistent, that the intersect between stress and fear mechanisms and their modulation by gonadal hormones may have more effect on women's anxiety than previously assumed.

As in 1992-3, the 2013-14 data showed that lower educational levels were associated with high DA in adult Danes. Some studies support this finding [29] [30], while others do not [23] [31] [32].

The likelihood that negative dentist behaviors contributed to extreme DA ranged from 4.3 to 6.7 times more likely than for other fear levels in the present study. The same dentist behavior items in 1993, including anger, patient putdowns and hard-handedness, were also from 3.8 to 6.1 times more likely to be associated with extreme DA than for other fear levels. Thus, bad experiences with dentists were still highly explanatory for extreme DA in Danish adults. 
These results were also similar to results that used these very same negative dentist behavior items in a larger US study nearly 30 years ago [33]. Locker et al. [34] also reported on negative experiences with dentists in a Canadian population of $\mathrm{N}=3055$ and found that those with painful and frightening experiences had almost 10 times higher risk of being high DA patients (DAS > 13), while those with painful, frightening and embarrassing experiences increased the risk to 22 times higher than others. This emphasized that frightening and embarrassing experiences with dentists, such as in the items above, had substantial influence over highly anxious patients' perceptions of negative dental experiences. Oosterink et al. [13] found in their 2009 study that dental phobias were unique from other phobias in that they had trauma-related symptoms including a prevalence rate of $49.4 \%$ of individuals with intrusive re-experiencing of bad encounters. The present results and those of these other studies indicate that the dental profession must redouble efforts to prevent bad experiences and condone negative dentist behaviors for both the benefit of patients and of the profession as a whole. This requires that dental education provide dentists with optimal communication skills and up-to-date knowledge of dental anxiety and pain control.

\section{Conclusion}

Web survey results from this convenience sample were demographically representative for Danish adults 20 - 80 yo and showed only small, but probably significant, increases in high or extreme DA after 20 years. Thus, the data from the present study seemed comparable to those collected in 1992 in a nationally representative telephone survey study. Both strategies, however, lacked coverage of the age group 16 - $19 \mathrm{yr}$. Thus, future strategies regarding this age group of adults require special attention. It is the responsibility of the dental profession, both through educational and other institutional values, to combat patient suffering from dental anxiety related to negative dentist behaviors.

\section{References}

[1] Braunsberger, K., Wybenga, H. and Gates, R. (2007) A Comparison of Reliability between Telephone and Web-Based Surveys. Journal of Business Research, 60, 758-764. https://doi.org/10.1016/j.jbusres.2007.02.015

[2] Gosling, S.D., Vazire, S., Srivastava, S. and John, O.P.I. (2004) Should We Trust Web-Based Studies? A Comparative Analysis of Six Preconceptions about Internet Questionnaires. American Psychologist, 59, 93-104. https://doi.org/10.1037/0003-066X.59.2.93

[3] Heiervang, E. and Goodman, R. (2011) Advantages and Limitations of Web-Based Surveys: Evidence from a Child Mental Health Survey. The International Journal for Research in Social and Genetic Epidemiology and Mental Health Services, 46, 69-76. https://doi.org/10.1007/s00127-009-0171-9

[4] Dillman, D.A. and Smyth, J.D. (2007) Design Effects in the Transition to Web-Based Surveys. American Journal of Preventive Medicine, 32, S90-S96.

https://doi.org/10.1016/j.amepre.2007.03.008 
[5] Couper, M.P. (2007) Issues of Representation in eHealth Research (with a Focus on Web Surveys). American Journal of Preventive Medicine, 32, S83-S89. https://doi.org/10.1016/j.amepre.2007.01.017

[6] Moore, R., Birn, H., Kirkegaard, E., Brødsgaard, I. and Scheutz, F. (1993) Prevalence and Characteristics of Dental Anxiety in Danish Adults. Community Dentistry and Oral Epidemiology, 21, 292-296. https://doi.org/10.1111/j.1600-0528.1993.tb00777.x

[7] Corah, N.L. (1969) Development of a Dental Anxiety Scale. Journal of Dental Research, 48, 596. https://doi.org/10.1177/00220345690480041801

[8] Corah, N.L., Gale, E.N. and Illing, S.J. (1978) Assessment of a Dental Anxiety Scale. Journal of the American Dental Association, 97, 816-819.

https://doi.org/10.14219/jada.archive.1978.0394

[9] Bering, P. (2015) Ny teknologi ved angst for tandbehandling Ny strategi for både patient og behandler. [New Technology for Dental Anxiety New Strategy for Both Patients and Dentists.] Tandplejeren [Dental Hygienist], 6, 14-18.

[10] Moore, R. (2006) Psychosocial Aspects of Dental Anxiety and Clinical Pain Phenomena. Doctor of Odontology Dissertation, Fællestrykkeriet for Sundhedsvidenskab, Aarhus University, Aarhus.

[11] Moore, R., Berggren, U. and Carlsson, S.G. (1991) Reliability and Clinical Usefulness of Psychometric Measures in a Self-Referred Population of Odontophobics. Community Dentistry and Oral Epidemiology, 19, 347-351.

https://doi.org/10.1111/j.1600-0528.1991.tb00185.x

[12] Moore, R., Jensen, C.G., Andersen, L.B. and Brødsgaard, I. (2016) Reconsidering Co-Morbid Traits in Explanatory Models of High Dental Anxiety Using a Comparison of Psychiatric and Normal Patient Samples. Open Journal of Stomatology, 6, 17. https://doi.org/10.4236/ojst.2016.611027

[13] Oosterink, F.M.D., de Jongh, A. and Hoogstraten, J. (2009) Prevalence of Dental Fear and Phobia Relative to Other Fear and Phobia Subtypes. European Journal of Oral Sciences, 117, 135-143. https://doi.org/10.1111/j.1600-0722.2008.00602.x

[14] Stouthard, M.E. and Hoogstraten, J. (1990) Prevalence of Dental Anxiety in the Netherlands. Community Dentistry and Oral Epidemiology, 18, 139-142. https://doi.org/10.1111/j.1600-0528.1990.tb00039.x

[15] Liinavuori, A., Tolvanen, M., Pohjola, V. and Lahti, S. (2016) Changes in Dental Fear among Finnish Adults: A National Survey. Community Dentistry and Oral Epidemiology, 44, 128-134. https://doi.org/10.1111/cdoe.12196

[16] Smith, T.A. and Heaton, L.J. (2003) Fear of Dental Care: Are We Making Any Progress? Journal of the American Dental Association, 134, 1101-1108. https://doi.org/10.14219/jada.archive.2003.0326

[17] Hägglin, C., Berggren, U., Hakeberg, M., Hallstrom, T. and Bengtsson, C. (1999) Variations in Dental Anxiety among Middle-Aged and Elderly Women in Sweden: A Longitudinal Study between 1968 and 1996. Journal of Dental Research, 78, 1655-1661. https://doi.org/10.1177/00220345990780101101

[18] Thomson, W.M., Stewart, J.F., Carter, K.D. and Spencer, A.J. (1996) Dental Anxiety among Australians. International Dental Journal, 46, 320-324. https://www.ncbi.nlm.nih.gov/pubmed/?term=PMID\%3A+9147119

[19] Armfield, J.M. (2010) The Extent and Nature of Dental Fear and Phobia in Australia. Australian Dental Journal, 55, 368-377. https://doi.org/10.1111/j.1834-7819.2010.01256.x

[20] Locker, D., Thomson, W.M. and Poulton, R. (2001) Onset of and Patterns of 
Change in Dental Anxiety in Adolescence and Early Adulthood: A Birth Cohort Study. Community Dental Health, 18, 99-104.

https://www.ncbi.nlm.nih.gov/pubmed/11461066

[21] Maggirias, J. and Locker, D. (2002) Five-Year Incidence of Dental Anxiety in an Adult Population. Community Dental Health, 19, 173-179.

https://www.ncbi.nlm.nih.gov/pubmed/?term=PMID\%3A+12269464

[22] Humphris, G., Crawford, J.R., Hill, K., Gilbert, A. and Freeman, R. (2013) UK Population Norms for the Modified Dental Anxiety Scale with Percentile Calculator: Adult Dental Health Survey 2009 Results. BMC Oral Health, 13, 29.

https://doi.org/10.1186/1472-6831-13-29

[23] Enkling, N., Marwinski, G. and Jöhren, P. (2006) Dental Anxiety in a Representative Sample of Residents of a Large German City. Clinical Oral Investigations, 10, 84-91. https://doi.org/10.1007/s00784-006-0035-6

[24] Gross, J.J., Carstensen, L.L., Pasupathi, M., Hsu, A.Y.C., Tsai, J. and Skorpen, C.G. (1997) Emotion and Aging: Experience, Expression, and Control. Psychology and Aging, 12, 590-599. https://doi.org/10.1037/0882-7974.12.4.590

[25] McLean, C.P., Asnaani, A., Litz, B.T. and Hofmann, S.G. (2011) Gender Differences in Anxiety Disorders: Prevalence, Course of Illness, Comorbidity and Burden of Illness. Journal of Psychiatric Research, 45, 1027-1035.

https://doi.org/10.1016/j.jpsychires.2011.03.006

[26] McLean, C.P. and Anderson, E.R. (2009) Brave Men and Timid Women? A Review of the Gender Differences in Fear and Anxiety. Clinical Psychology Review, 29, 496-505. https://doi.org/10.1016/j.cpr.2009.05.003

[27] McLean, C.P. and Hope, D.A. (2010) Subjective Anxiety and Behavioral Avoidance: Gender, Gender Role, and Perceived Confirmability of Self-Report. Journal of Anxiety Disorders, 24, 494-502. https://doi.org/10.1016/j.janxdis.2010.03.006

[28] Maeng, L.Y. and Milad, M.R. (2015) Sex Differences in Anxiety Disorders: Interactions between Fear, Stress, and Gonadal Hormones. Hormones and Behavior, 76, 106-117. https://doi.org/10.1016/j.yhbeh.2015.04.002

[29] Acharya, S. (2008) Factors Affecting Dental Anxiety and Beliefs in an Indian Population. Journal of Oral Rehabilitation, 35, 259-267. https://doi.org/10.1111/j.1365-2842.2007.01777.x

[30] Deogade, S.C. and Suresan, V. (2016) Psychometric Assessment of Anxiety with the Modified Dental Anxiety Scale among Central Indian Adults Seeking Oral Health Care to a Dental School. Industrial Psychiatry Journal, 25, 202-209. https://doi.org/10.4103/ipj.ipj_16_16

[31] Hakeberg, M., Berggren, U. and Carlsson, S.G. (1992) Prevalence of Dental Anxiety in an Adult Population in a Major Urban Area in Sweden. Community Dentistry and Oral Epidemiology, 20, 97-101. https://doi.org/10.1111/j.1600-0528.1992.tb00686.x

[32] Milgrom, P., Newton, J., Boyle, C., Heaton, L.J. and Donaldson, N. (2010) The Effects of Dental Anxiety and Irregular Attendance on Referral for Dental Treatment under Sedation within the National Health Service in London. Community Dentistry and Oral Epidemiology, 38, 453-459. https://doi.org/10.1111/j.1600-0528.2010.00552.x

[33] Milgrom, P., Fiset, L., Melnick, S. and Weinstein, P. (1988) The Prevalence and Practice Management Consequences of Dental Fear in a Major US City. The Journal of the American Dental Association, 116, 641-647. 
https://doi.org/10.14219/jada.archive.1988.0030

[34] Locker, D., Shapiro, D. and Liddell, A. (1996) Negative Dental Experiences and Their Relationship to Dental Anxiety. Community Dent Health, 13, 86-92.

https://www.ncbi.nlm.nih.gov/pubmed/8763138 